\title{
Investigation on Double Oxide Film Initiated Pore Formation in Aluminum Casting Alloys
}

\author{
G. GYARMATI ${ }^{1}$, Gy. FEgYVERnEKI ${ }^{2}$, M. ToKÁR ${ }^{3}$, T. MENDE ${ }^{4}$ \\ ${ }^{1}$ University of Miskolc, Faculty of Materials Science and Engineering, Foundry Institute, gygabor007@gmail.com \\ ${ }^{2}$ University of Miskolc, Faculty of Materials Science and Engineering, Foundry Institute, \\ gyorgy.fegyverneki@nemak.com \\ 3University of Miskolc, Faculty of Materials Science and Engineering, Foundry Institute, monika.tokar@uni- \\ miskolc.hu \\ ${ }^{4}$ University of Miskolc, Faculty of Materials Science and Engineering, Institute of Physical Metallurgy, \\ Metalforming and Nanotechnology, tamas.mende@uni-miskolc.hu
}

Abstract. The most common, and in fact, the most deleterious defects of aluminum casting alloys are the so-called double oxide films or bifilms, which have a central role in porosity formation, as they can easily unfurl and inflate into pores during the solidification of the alloys. Sr addition is generally used in the foundry industry for the modification of the eutectic Si phase of hypoeutectic Al-Si alloys. However, Sr microalloying usually leads to an increased pore formation tendency. As bifilms are preferred sites for pore formation, it should be expected that Sr additions have a significant effect on the number and/or the structure of double oxide films present in the melt. In this work, the relationship between Sr-concentration and the susceptibility to pore formation has been investigated through the evaluation of melt quality of melts which had different levels of Sr. The bifilm content of the melts was investigated by the analysis of K-mold specimens and X-ray computed tomography (CT) of reduced pressure test (RPT) samples. It was found that liquid alloys with a higher Sr-concentration had a significantly greater tendency to pore formation, which can be explained by the presence of a larger number of bifilm defects in the liquid alloy.

\section{Introduction}

In order to ensure adequate mechanical properties (tensile strength, elongation, fatigue life, etc.) of cast parts, the number of structural defects like porosity and inclusions must be minimized [1-4]. Porosity is one of the most common defects, which can lead to inadequate mechanical properties and premature failure of cast parts. In the case of aluminum alloys, pore formation is mainly attributed to inadequate feeding of solidification shrinkage and the rejection of dissolved hydrogen during the solidification of the alloy [5,6]. However, it was proposed in the literature [7, 8], that double oxide films (bifilms) take a central role in pore formation as they can easily open up and inflate into pores due to hydrogen diffusion into their inner atmosphere and pressure drop in the mushy zone caused by the volumetric shrinkage during solidification (Fig. 1). This hypothesis is supported by experimental results [9-13] and comprehensive theoretical calculations [14-16]. 


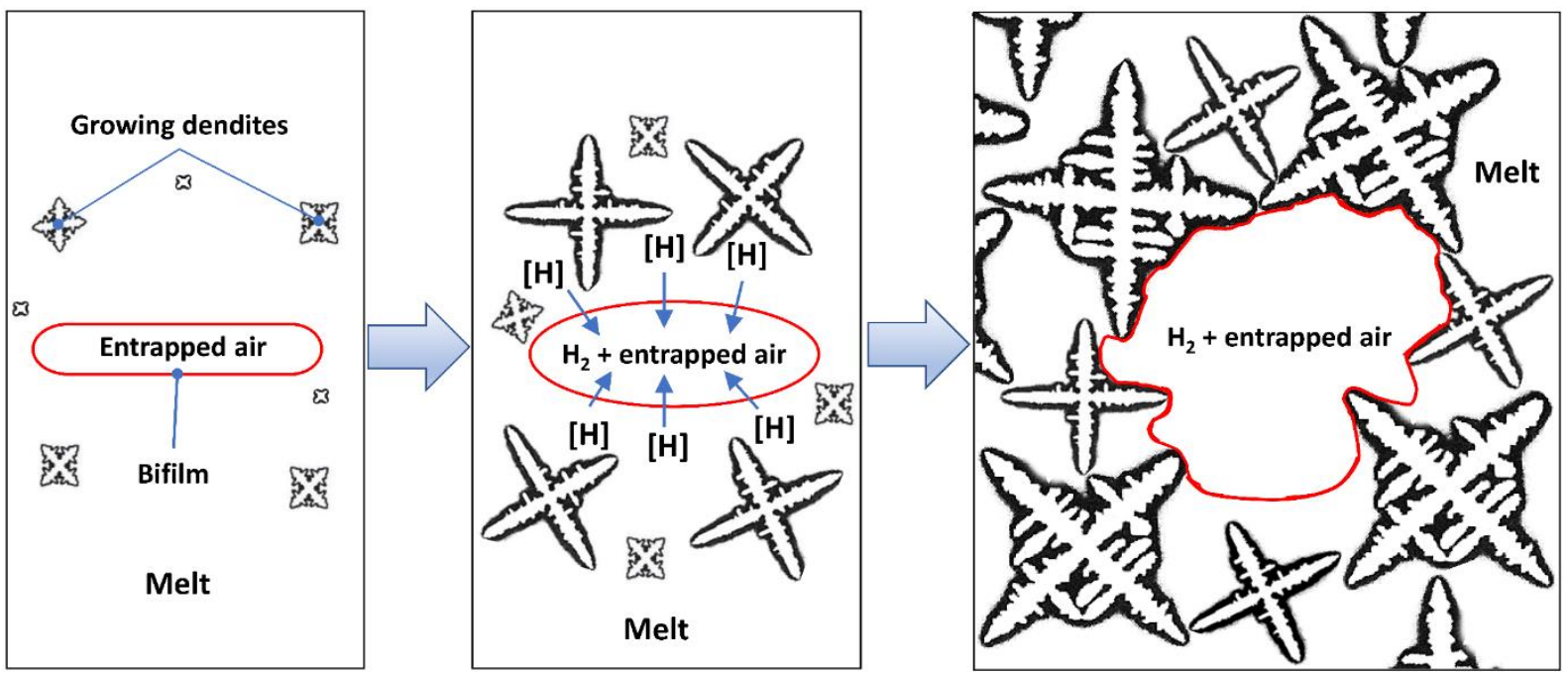

Figure 1. Schematic illustration of bifilm initiated pore formation.

Bifilm formation during the melt handling and processing techniques of aluminum alloys is mostly an unavoidable process as any disturbance of the melt surface leads to the entrainment of the surface oxide layer. In this way, numerous bifilms are introduced to the melts during common foundry activities like melting, alloying, fluxing and pouring. However, the characterization of the bifilm content of liquid alloys is an especially hard task, since these defects are comprised of vanishingly thin oxide layers often as little as 20 nanometers thick [17-19].

It was highlighted in the authors' previous research work $[20,21]$, that the double oxide film content of liquid aluminum alloys, and thus the melt quality, can be characterized by computed tomography (CT) aided porosity analysis of reduced pressure test (RPT) specimens. During solidification under reduced pressure, the gas phase trapped between the oxide layers of double oxide films is expanding. Furthermore, the solubility of hydrogen in the alloy is lowered due to the reduced hydrogen partial pressure. In this way, the $\mathrm{H}_{2}$ precipitation process inside the bifilms and the growth of the created pores is accelerated [22]. This allows us the quantitative characterization of bifilm quantity based on the number and size of pores found in the RPT samples [23].

$\mathrm{Sr}$ is generally used in the foundry industry to improve the mechanical properties of hypoeutectic Al-Si casting alloys, as small amounts of Sr (100-300 ppm, depending on the chemical composition of the alloy, cooling rate during solidification and melt cleanliness) causes the modification of the eutectic Si particles from a coarse flake-like morphology into a fine fibrous one [24-26]. On the other hand, the modification-related research in the past decades demonstrated that Sr additions can lead to increased pore formation tendency. The increased volume fraction of porosity and higher pore number density in the cast parts is generally associated with Sr microalloying, especially at higher Sr concentrations (above $200 \mathrm{ppm}$ ) [24, 27-29]. Despite the tremendous amount of research work aiming at the causes of this phenomenon, the mechanism underlying the effect of $\mathrm{Sr}$ on porosity formation is not fully understood. As bifilms are preferred sites for pore formation, it should be expected that $\mathrm{Sr}$ additions have a significant effect on the number and/or the structure of double oxide films present in the melt [30-34]. Therefore, the aim of this research work is to study the effect of different Sr concentrations on the double oxide film content and the susceptibility of the alloy to pore formation. 


\section{Experimental Procedure}

\subsection{Melt processing}

Melt treatments consisting of rotary degassing with $\mathrm{N}_{2}$ gas and flux addition were executed on AlSi7MgCu alloy melts (see Table 1. for concentration ranges of the studied alloy). In order to raise the $\mathrm{Sr}$ concentration of the melts, in three treatment cycles, 3 pieces of Al-10Sr master alloy rods (with a weight of $200 \mathrm{~g}$ ) were added to the melts. In the case of three additional experiments, no additional alloying was made. The quantity of metal treated in one cycle was approximately $1000 \mathrm{~kg}$. The metal was melted in a stack smelter then transported by a transport ladle to a resistance heated holding furnace where the melt treatments were performed (Fig. 2). The treatment parameters and the quantity of flux added ( $400 \mathrm{~g}$ ) were always the same for each respective cycle. The $\mathrm{N}_{2}$ gas flow rate was $20 \mathrm{~L} / \mathrm{min}$; the rotor revolution was $500 \mathrm{RPM}$ during vortex formation and $250 \mathrm{RPM}$ in the degassing phase. The treatment time was 12 minutes in each case. The molten metal temperature in the holding furnace was maintained between $740{ }^{\circ} \mathrm{C}$ and $750{ }^{\circ} \mathrm{C}$.

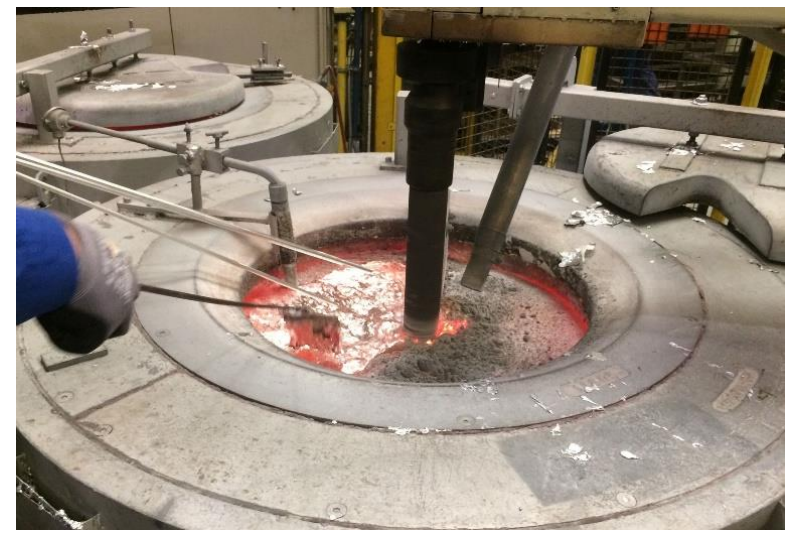

Figure 2. Al-10Sr master alloy rod addition during melt treatment.

\begin{tabular}{ccccccc}
\hline $\mathbf{S i}$ & $\mathbf{F e}$ & $\mathbf{C u}$ & $\mathbf{M n}$ & $\mathbf{M g}$ & $\mathbf{T i}$ & $\mathbf{S r}$ \\
\hline $6.5-7.5$ & $<0.2$ & $0.45-0.58$ & $<0.1$ & $0.36-0.45$ & $<0.2$ & $0.017-0.030$ \\
\hline \multicolumn{7}{c}{ Table 1. Chemical composition of the studied aluminum alloy (wt. \%). }
\end{tabular}

\subsection{Melt quality assessment}

The changes in melt quality were characterized by the microscopic inspection of K-mold specimens and X-ray computed tomography (CT) of reduced pressure test (RPT) samples. Utilizing the K-mold analysis, the inclusion content of the melt can be quantified. The K-mold specimen itself is a flat bar that has four notches which act as fracture points. For the casting of the samples, the so-called K-mold was used, which was preheated to $200{ }^{\circ} \mathrm{C}$ prior to casting. The fracture surfaces of the specimens were inspected with a Zeiss Stemi 2000-C stereomicroscope at a magnification of 25X. Based on the number of inclusions found on the fracture surfaces, a K-value was determined (Eq. 1) for each sample, which was used for the quantitative characterization of the melt purity. 


$$
\mathrm{K}=\frac{\mathrm{S}}{\mathrm{n}}
$$

where $\mathbf{K}$ is the K-mold value (dimensionless number), $\mathbf{n}$ is the number of examined fracture surfaces, and $\mathbf{S}$ is the total number of inclusions found in $\mathrm{n}$ pieces $[35,36]$. The surface of the found inclusions was investigated with a Zeiss EVO MA 10 scanning electron microscope (SEM) equipped with an energy-dispersive X-ray spectroscopy (EDS) system. During each melt preparation, K-mold specimens were cast before and after the melt treatments; the number of samples cast at once was 5 .

The RPT samples were cast into steel cups preheated to $200{ }^{\circ} \mathrm{C}$ before and following the melt treatments. The pressure of the vacuum chamber of the RPT machine was $80 \mathrm{mbar}$, in which the RPT specimens stayed for 6 minutes. The porosity analysis of the RPT samples was executed with computed tomography (CT). The radiographic images were made with GE Seifert X-Cube Compact $225 \mathrm{kV}$ apparatus, the acceleration voltage was $135 \mathrm{kV}$, the tube current was $0.8 \mathrm{~mA}$. During one rotation of the samples, 900 images were acquired. The image reconstruction and processing were conducted with VGSTUDIO MAX 3.2 software. The segmentation of pores was conducted with the VGDefX algorithm, which is a part of the porosity analysis module of the software. For each pore, a probability value was evaluated by the software, which depends on the local contrast of voxels. Objects with a volume smaller than $0.05 \mathrm{~mm} 3$ and pores with a probability value lower than 0.9 were ignored. Based on the data acquired during the CT analysis, pore number density and pore volume fraction was calculated, which was used for the quality evaluation of the molten alloy.

\subsection{Thermal analysis}

The elemental composition of the alloy was determined with optical emission spectrometry of samples cast at each stage of melt preparation. The main drawback of $\mathrm{Sr}$ level determination with optical emission spectrometry is, that the results do not give information about the form of the $\mathrm{Sr}$ in the melt. As a result of $\mathrm{Sr}$ fading, $\mathrm{Sr}$ can be present in the form of such compounds that do not participate in the eutectic modification process. However, with the aid of thermal analysis, the quantity of "active" $\mathrm{Sr}$ which causes eutectic modification can be easily evaluated [24]. The eutectic growth temperature $\left(\mathrm{T}_{\mathrm{E}, \mathrm{G}}^{\mathrm{Al}-\mathrm{Si}}\left[{ }^{\circ} \mathrm{C}\right]\right)$ which can be determined from the cooling curve and its first derivative with respect to time (Fig. 3. (a)), provides adequate information about the eutectic modification level of the alloy. As a result of $\mathrm{Sr}$ addition, the solidification of the Al-Si eutectic phase begins at a lower temperature with larger undercooling. As a consequence, the eutectic nucleation temperature $\left(\mathrm{T}_{\mathrm{NUC}}^{\mathrm{Al}-\mathrm{Si}}\left[{ }^{\circ} \mathrm{C}\right]\right)$ and the eutectic growth temperature $\left(\mathrm{T}_{\mathrm{E}, \mathrm{G}}^{\mathrm{Al}-\mathrm{Si}}\left[{ }^{\circ} \mathrm{C}\right]\right)$ are lowered. The difference between the eutectic growth temperature of an unmodified and a modified alloy $\left(\Delta \mathrm{T}_{\mathrm{E}, \mathrm{G}}^{\mathrm{Al}-\mathrm{Si}}\left[{ }^{\circ} \mathrm{C}\right]\right)$ is directly related to the eutectic modification level of the given alloy (Fig. 3. (b)) [37-40].

During the experiments, thermal analysis tests were executed before and after the melt treatments. The samples were taken by pouring aluminum melt into a cylindrical steel cup ( $40 \mathrm{~mm}$ in diameter, 40 $\mathrm{mm}$ deep). The thermal analysis test cup was preheated to $200{ }^{\circ} \mathrm{C}$. The average weight of the TA test samples was $110 \pm 10 \mathrm{~g}$. The data for thermal analysis were collected by a data acquisition system 
linked to a personal computer. The temperatures between $700{ }^{\circ} \mathrm{C}$ and $400{ }^{\circ} \mathrm{C}$ were recorded for all the experiments. The change in eutectic growth temperature $\left(\Delta \mathrm{T}_{\mathrm{E}, \mathrm{G}}^{\mathrm{Al}-\mathrm{Si}}\left[{ }^{\circ} \mathrm{C}\right]\right)$ was calculated using Eq. 2 :

$$
\Delta \mathrm{T}_{\mathrm{E}, \mathrm{G}}^{\mathrm{Al}-\mathrm{Si}}=\mathrm{T}_{\mathrm{E}, \mathrm{G}, \text { Unmodified }}^{\mathrm{Al}-\mathrm{Si}} \mathrm{T}_{\mathrm{E}, \mathrm{G}, \text { Modified }}^{\mathrm{Al}-\mathrm{Si}}
$$

where $\mathrm{T}_{\mathrm{E}, \mathrm{G}, \mathrm{M} \text { Modified }}^{\mathrm{Al}}\left[{ }^{\circ} \mathrm{C}\right]$ is the eutectic growth temperature of the modified alloy determined from the cooling curve and its first derivative and $\mathrm{T}_{\mathrm{E}, \mathrm{G}, \mathrm{Un} \text { Unodified }}^{\mathrm{Al}}\left[{ }^{\circ} \mathrm{C}\right]$ is the eutectic growth temperature of the unmodified alloy determined from the chemical composition of the alloy using the following equation [39]:

$$
\mathrm{T}_{\mathrm{E}, \mathrm{G}, \text { Unmodified }}^{\mathrm{Al}-\mathrm{Si}}=577-\frac{12.5}{\mathrm{c}_{\mathrm{Si}}} \cdot\left(4.43 \cdot \mathrm{c}_{\mathrm{Mg}}+1.43 \cdot \mathrm{c}_{\mathrm{Fe}}+1.93 \cdot \mathrm{c}_{\mathrm{Cu}}+3.0 \cdot \mathrm{c}_{\mathrm{Mn}}\right)
$$

where $c_{S i}, c_{M g}, c_{F e}, c_{C u}$ and $c_{M n}$ are the concentrations of elements indicated in the subscripts in weight percent. Throughout the investigations, thermal analyses were conducted and the respective $\Delta \mathrm{T}_{\mathrm{E}, \mathrm{G}}^{\mathrm{Al}-\mathrm{Si}}$ was determined before and after the melt treatments.
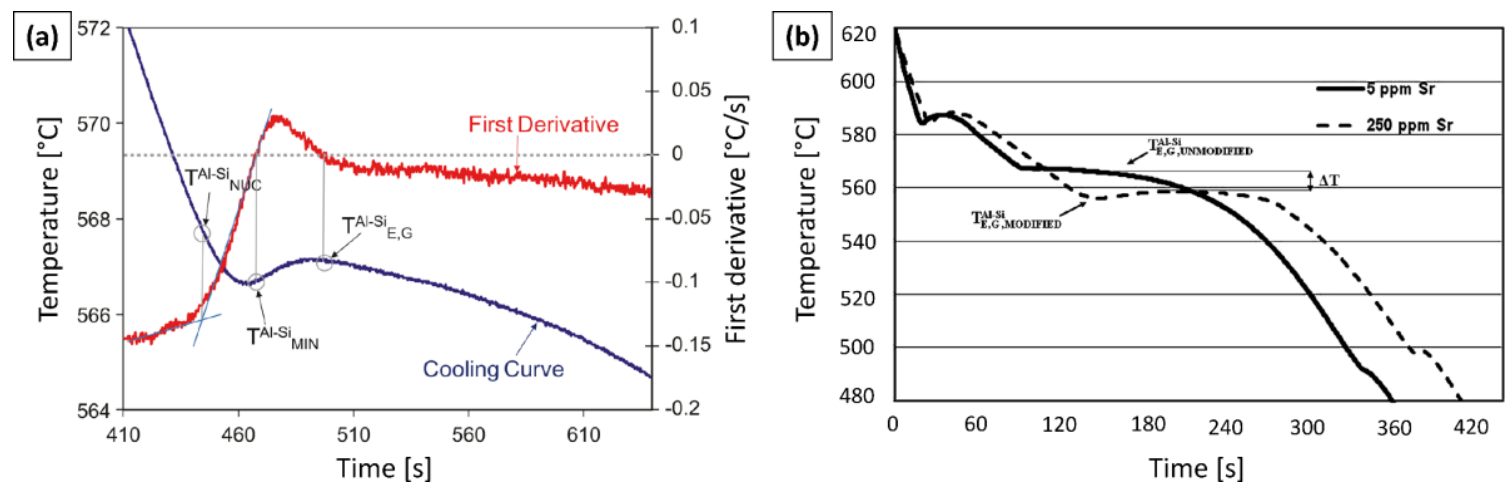

Figure 3. (a) The determination of $\mathrm{T}_{\mathrm{E}, \mathrm{G}}^{\mathrm{Al}-\mathrm{Si}}$ using the cooling curve and its first derivative [41] and (b) the cooling curve of an unmodified (5 ppm Sr) and a modified (250 ppm Sr) alloy [42].

\section{Results and Discussion}

The results of Sr-content analysis and $\Delta \mathrm{T}_{\mathrm{E}, \mathrm{G}}^{\mathrm{Al}-\mathrm{Si}}$ evaluation with thermal analysis are presented in Fig. 4. (a). Fig. 4. (b) shows the relationship between the measured Sr-concentration and $\Delta \mathrm{T}_{\mathrm{E}, \mathrm{G}}^{\mathrm{Al}-\mathrm{Si}}$ values.

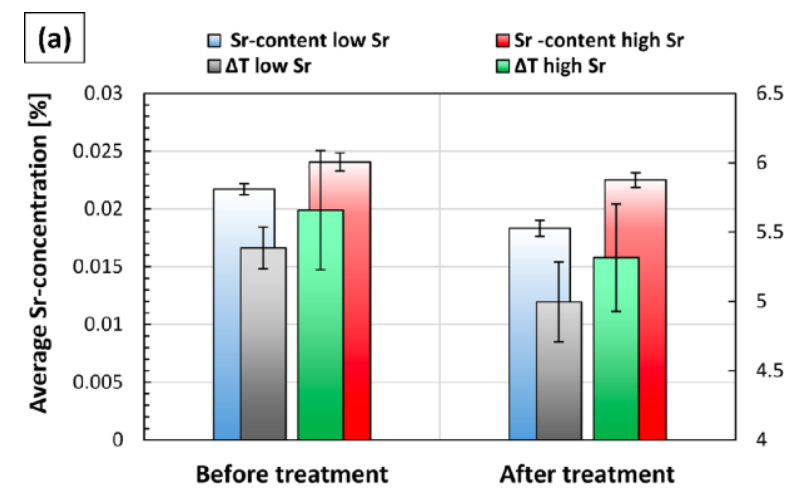

(b)

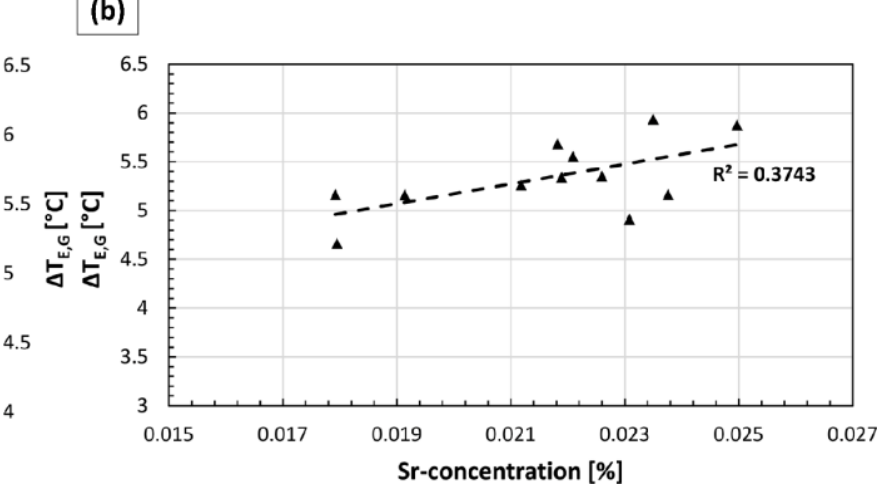

Figure 4. (a) Average Sr-concentration and $\Delta \mathrm{T}_{\mathrm{E}, \mathrm{G}}^{\mathrm{Al}-\mathrm{Si}}$ results and (b) the comparison of $\Delta \mathrm{T}_{\mathrm{E}, \mathrm{G}}^{\mathrm{Al}-\mathrm{Si}}$ and Sr-concentration values. 
In the cases, when additional Sr-alloying was made, the average Sr-concentration was 0.0225 wt. \% (225 ppm). When Sr alloying was omitted, the average Sr-content was 0.0183 wt. \% (183 ppm). The higher Sr-concentration values resulted in a higher average $\Delta \mathrm{T}_{\mathrm{E}, \mathrm{G}}^{\mathrm{Al}-\mathrm{Si}}$ value, i.e. better eutectic modification. On the other hand, the difference is only $0.32{ }^{\circ} \mathrm{C}$, which is not a significant difference in the rate of modification. It should be highlighted, that both the Sr-concentration and $\Delta \mathrm{T}_{\mathrm{E}, \mathrm{G}}^{\mathrm{Al}-\mathrm{Si}}$ values were lower after the melt treatments, which indicates that the rotary degassing treatments coupled with flux addition causes significant Sr-loss, and lowered eutectic modification rate, which is consistent with the authors' previous findings [41]. There were cases when the higher Srconcentrations were accompanied by lower $\Delta \mathrm{T}_{\mathrm{E}, \mathrm{G}}^{\mathrm{Al}-\mathrm{Si}}$ values (Fig. 4. (b)). The reason for this contradiction is that optical emission spectroscopy measures the total Sr-content of the alloy, regardless of the form of Sr. This means that during the analysis, $\mathrm{Sr}$ in $\mathrm{Sr}$-containing oxides, nitrides, and intermetallic compounds is also taken into account, which $\mathrm{Sr}$ does not contribute to the modification of the eutectic Si phase and, in this way its effect cannot be detected with thermal analysis.

The average K-values determined based on the evaluation of the fracture surfaces of K-mold samples are presented in Fig. 5. (a). Fig. 5. (b) and (c) show two examples of bifilm inclusion found in K-mold test pieces. The two layers of these bifilms could be distinguished on the opposing fracture surfaces, which confirms the doubled over structure of these defects. In most cases, these types of inclusions could be found on the fracture surfaces of the specimens, which supports the claim that these are the most common inclusions of aluminum casting alloys.
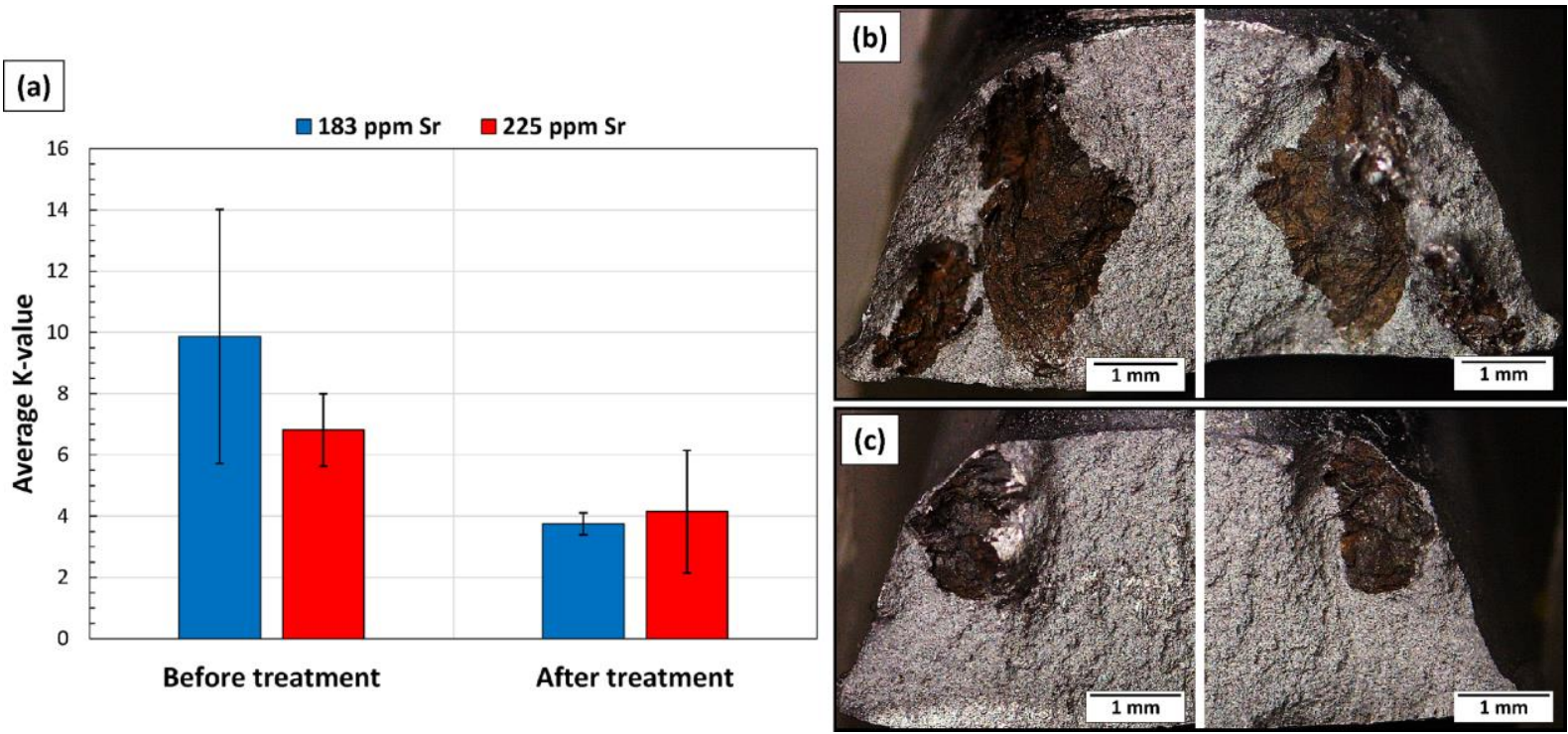

Figure 5. (a) Results of K-value evaluation, (b) and (c) bifilm defects on the fracture surfaces of K-mold samples.

Based on Fig. 5. (a), the inclusion content of the treated melts was higher when the average Sr-content was $225 \mathrm{ppm}$. This is an unexpected result, as, before treatment, the average K-value was significantly higher in the case of lower Sr-content. This suggests that despite identical treatment parameters, the total number of inclusions can be more effectively reduced when the Sr-content is lower. 
The results of the computed tomographic porosity analysis of RPT specimens are shown in Fig. 6. Both pore number density and pore volume fraction results were significantly higher, at a higher Srconcentration. Based on the CT images shown in Fig. 6., the difference between the number density and spatial distribution of pores is conspicuous, as the specimen cast from the alloy, that had higher Sr-concentration, contained significantly more, evenly distributed pores, besides the one central, large-sized shrinkage pore, which was present in each sample cast after melt treatments, regardless of Sr-content. These results are consistent with the published experimental results [24, 27, 43], as the higher volume fraction of porosity and higher pore number density is commonly observed at Srconcentrations higher than $200 \mathrm{ppm}$.
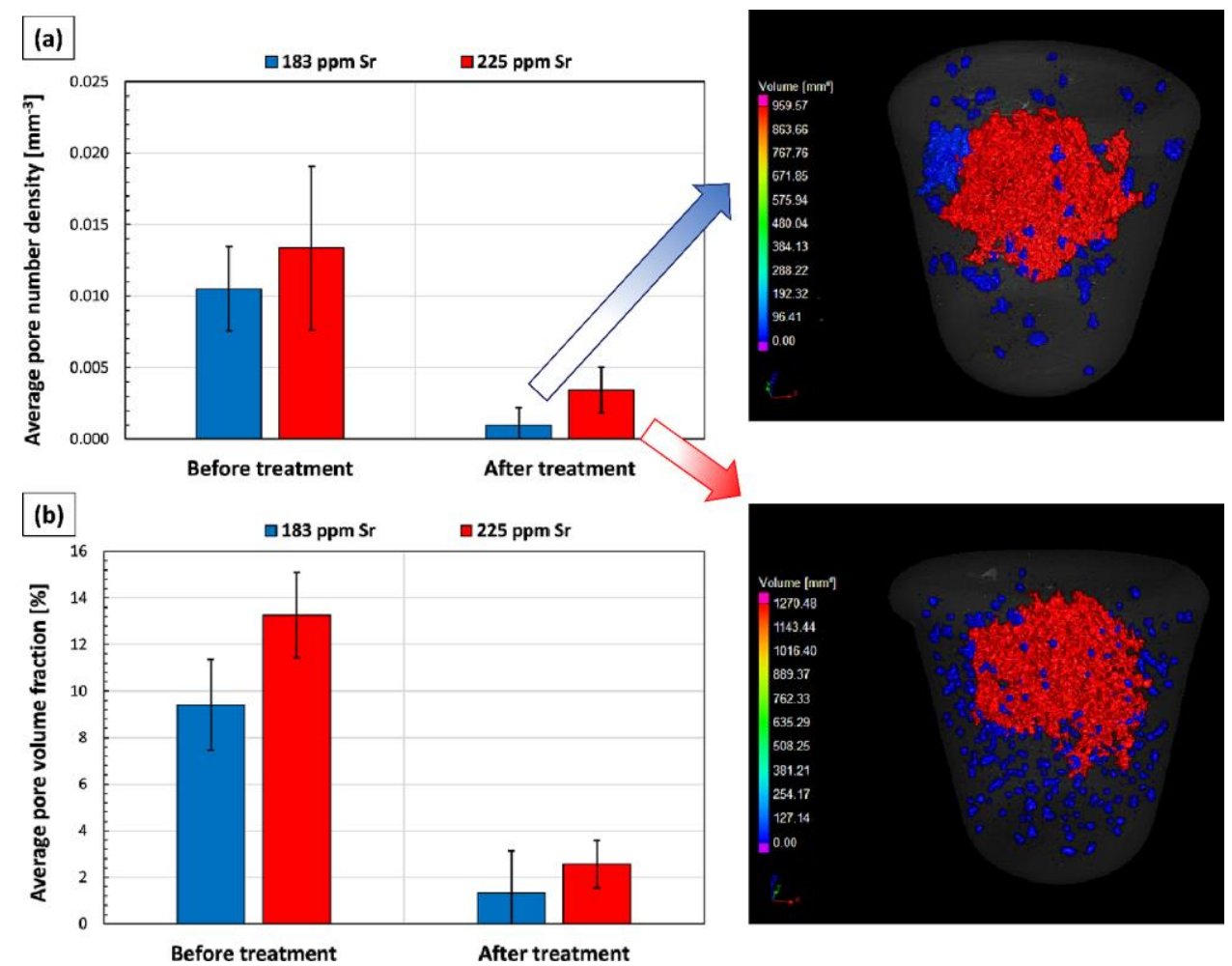

Figure 6. (a) Average pore number density and (b) pore volume fraction results based on CT-analysis with representative CT images of RPT samples cast after melt treatments

Fig. 7. shows the results of EDS-SEM analysis of two, film-like inclusions found on the fracture surfaces of K-mold specimens. 

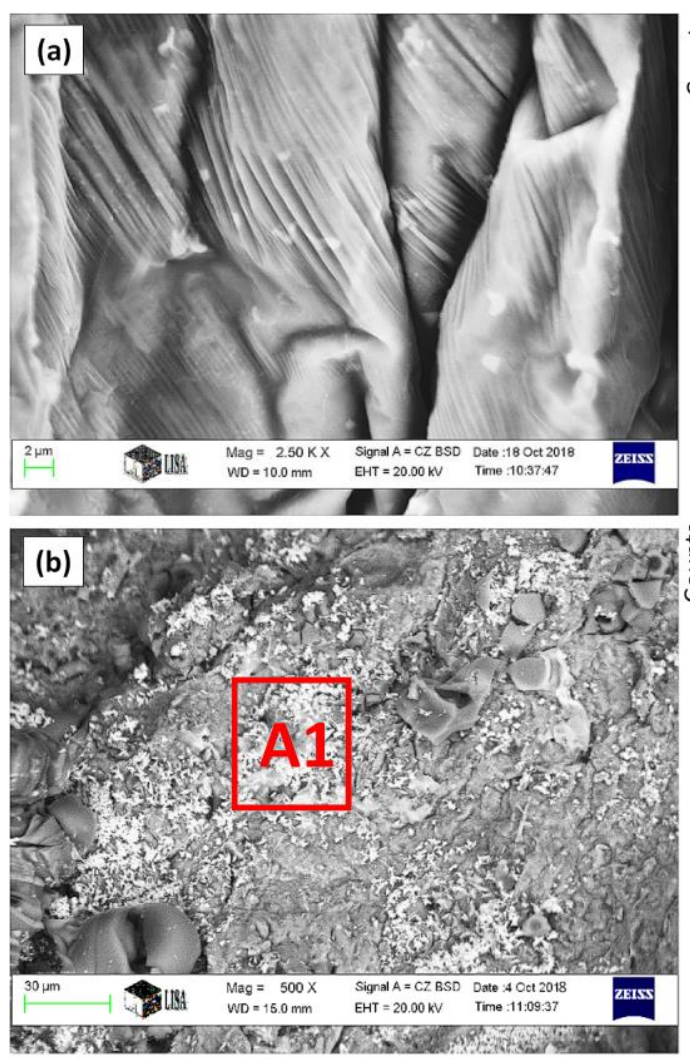
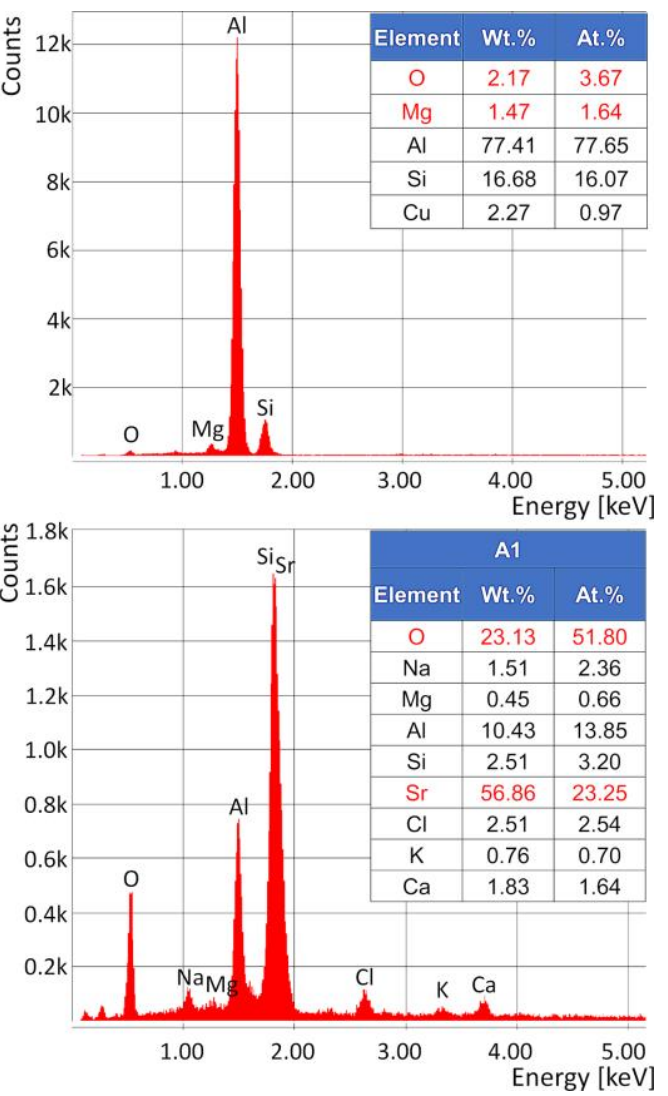

Figure 7. SEM image and results of EDS analysis of inclusion found on the fracture surfaces of K-mold samples

Based on its $\mathrm{O}$ and $\mathrm{Mg}$ content, the wrinkled film-like inclusion shown in Fig. 7. (a) is probably a thin spinel $\left(\mathrm{MgO} \cdot \mathrm{Al}_{2} \mathrm{O}_{3}\right)$ film, as the alloy contains less $\mathrm{Mg}$ than $2 \mathrm{wt}$. \%, but significantly more than 0.005 wt. \%, the formation of spinel is more feasible than that of $\mathrm{Al}_{2} \mathrm{O}_{3}$ or $\mathrm{MgO}$ [44]. On the other hand, the inclusion presented in Fig. 7. (b) is more complex regarding both structure and chemical composition. The high $\mathrm{O}$ - and Sr-concentration indicate the presence of strontium-oxides, which can be observed in the SEM image in the form of white particles. These strontium-oxide particles could be found in many inclusions, which suggests the intense oxidation of the Sr-content of the alloy. The $\mathrm{Na}, \mathrm{Ca}, \mathrm{K}$ and $\mathrm{Cl}$ content, however, indicates the presence of flux residues, as alkali- and alkaline-earth metal-chlorides are common constituents of fluxes used for inclusion removal during melt treatments [45]. The copresence of flux residues and Sr-containing oxides suggests that the application of fluxes can contribute to the Sr-loss shown in Fig. 4. (a). This finding is consistent with the authors' previously published results [41].

It is generally assumed in the literature, that higher Sr-concentration leads to the increased oxidation rate of the alloy, which in turn increases the inclusion content of the metal [32-34]. The thermodynamic stability of different oxides can be evaluated by comparing the standard Gibbs free energy of oxide formation at different temperatures (Fig. 8). The free energy plots in Fig. 8. were calculated with the aid of the reference data in [46]. As can be seen, strontium- and magnesium-oxide has a much more negative free energy of formation, than aluminum-oxide, so the oxidation of $\mathrm{Mg}$ and $\mathrm{Sr}$ is preferable above the oxidation of $\mathrm{Al}$. The plots of $\mathrm{SrO}$ and $\mathrm{MgO}$ indicate that the formation of these oxides at the temperatures of $700-800{ }^{\circ} \mathrm{C}$ is near equally favorable, but as it was highlighted above, the 
formation of $\mathrm{MgO}$ is not feasible at Mg-levels lower than $2 \mathrm{wt}$. \% and the formation of SrO should be expected, as Mg-spinel has a much higher Gibbs free energy of formation, than SrO. In fact, it was highlighted by numerous researcher [11,32-34, 47], that in the presence of $\mathrm{Sr}$, the structure of $\mathrm{Al}_{2} \mathrm{O}_{3}$ bifilms inside the molten alloy gradually transforms, Sr segregates to the surface, then builds in the structure of these defects, which results in defects with Sr-containing oxides in them. This phenomenon clearly explains the presence of numerous strontium-oxide particles found on the surface of film-like inclusions (Fig. 7. (b)), however, it does not give answer regarding the increased number of inclusions in the case of $225 \mathrm{ppm}$ average Sr-content, which is indicated by the higher average K-value (Fig. 5. (a)) and pore number density inside RPT samples (Fig. 6. (a)).

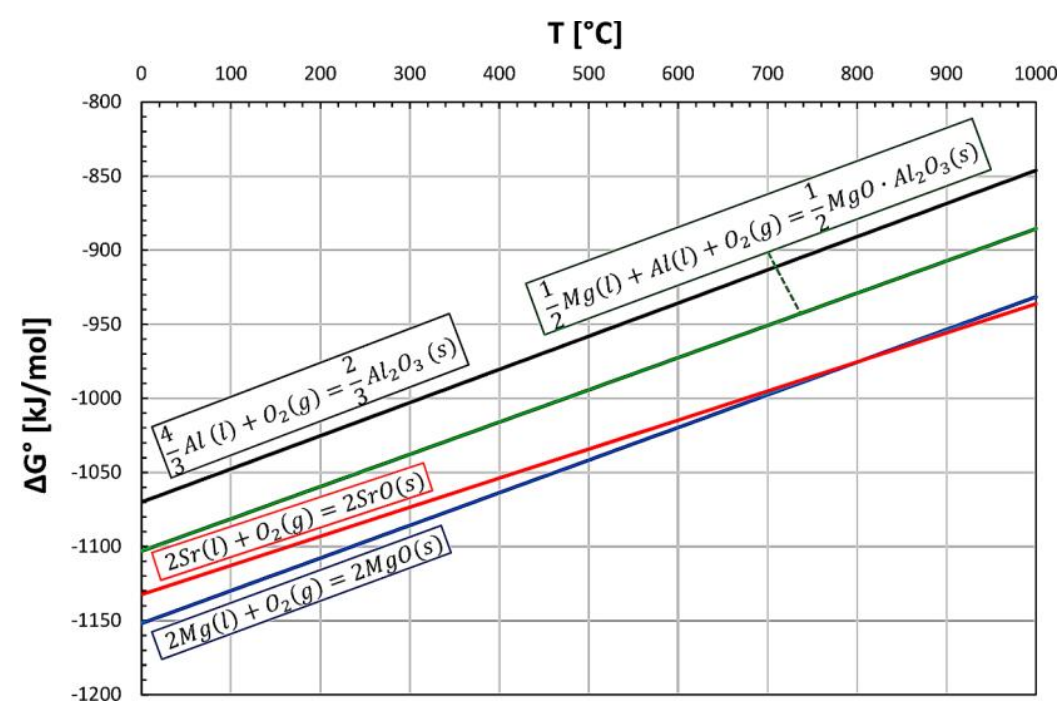

Figure 8. Gibbs free energy of formation of aluminum-, magnesium-, strontium-oxides and Mg-spinel (calculated per mole of oxygen) at different temperatures

According to Bian et al. [48], the Sr-induced changes in the structure of oxide films cause the loss of flexibility of these defects, which in turn brake up more easily into smaller pieces during the pouring of the liquid metal, or during the rotary degassing treatments. As these smaller oxide bifilms are favorable pore initiation sites, the change in the structure of double oxide films causes increased inclusion content and pore number density simultaneously. Campbell [30] highlights the importance of another phenomenon which can contribute to increased bifilm content and higher susceptibility to pore formation in the case of Sr-modified alloys. Bifilms suspended in the melt are preferred substrates for the heterogeneous nucleation of the eutectic silicon phase during the solidification of the alloy. Due to this, numerous bifilms are incorporated in the structure of the Al-Si eutectic phase. These built-in bifilms cannot open up and create pores during the solidification process. However, in the presence of Sr, double oxide films are no longer preferred substrates, and they remain freely floating, suspended in the liquid metal. These "free" bifilms can inflate and create pores during solidification, which causes increased pore number density and pore volume fraction. The described theories can clearly explain the experimental results of this study, however for the experimental validation of these phenomena, more research needs to be done. 


\section{Summary}

Based on the experimental results, the following conclusions can be drawn:

- In the cases where Sr master alloy additions were made, higher number density and pore volume fraction values were evaluated during the CT-analysis of RPT specimens.

- The higher number of pores in the case of higher Sr concentration can be explained by the presence of a larger number of bifilm defects, which is confirmed by the results of the evaluation of K-mold specimens.

- The higher bifilm content is presumably the result of the effect of Sr additions on the oxidation rate of the alloy and its effect on the structure of oxides present in the liquid metal.

\section{Acknowledgment}

Supported by the ÚNKP-19-3 New National Excellence Program of the Ministry for Innovation and Technology.

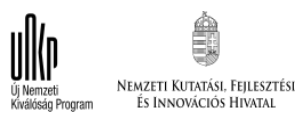

\section{References}

[1] M. A. El-Sayed, W. D. Griffiths, Hydrogen, Bifilms and Mechanical Properties of Al Castings, International Journal of Cast Metals Research 27 (2014) 282-287. DOI: 10.1179/1743133614Y.0000000113.

[2] Q. G. Wang, C. J. Davidson, J. R. Griffiths, P. N. Crepeau, Oxide Films, Pores and the Fatigue Lives of Cast Aluminum Alloys, Metallurgical and Materials Transactions B 37 (2006) 887-895. DOI: 10.1007/BF02735010.

[3] F. Chiesa, D. Levasseur, G. Morin, B. Duchesne, Effect of Inclusions on the Tensile Properties Inside a LPPM A356 Casting, International Journal of Metalcasting 10 (2016) 216-223. DOI: 10.1007/s40962-016-0029-3

[4] M. Uludağ, M. Uyaner, F. Yilmaz, D. Dişpinar, Mechanical Properties and Melt Quality Relationship of Sr-modified Al-12Si Alloy, Archives of Foundry Engineering 15, (2015) 134-140. DOI: 10.1515/afe2015-0093

[5] D. M. Stefanescu, A. V. Catalina, Physics of Microporosity Formation in Casting Alloys - Sensitivity Analysis for Al-Si Alloys, International Journal of Cast Metals Research, 24 (2011) 144-150. DOI: $10.1179 / 136404611$ X13001912813780

[6] R. Monroe, Porosity in Castings, AFS Transactions 113 (2005) 1-28.

[7] J. Campbell, Complete Casting Handbook, Elsevier, (2015) 3-90., 341-415., 779-783. DOI: 10.1016/B978-0-444-63509-9.00007-8

[8] D. Dispinar, J. Campbell, Critical Assessment of Reduced Pressure Test. Part 1: Porosity Phenomena, International Journal of Cast Metals Research 17 (2004) 280-286. DOI: $10.1179 / 136404604225020704$. 
International Journal of Engineering and Management Sciences (IJEMS) Vol. 5. (2020). No. 2 DOI: 10.21791/IJEMS.2020.2.18.

[9] D. Dispinar, J. Campbell, Critical Assessment of Reduced Pressure Test. Part 2: Quantification, International Journal of Cast Metals Research 17 (2004) 287-294. DOI: $10.1179 / 136404604225020704$.

[10] M. Tiryakioğlu, P. Yousefian, P.D. Eason, Quantification of Entrainment Damage in A356 Aluminum Alloy Castings, Metallurgical and Materials Transactions A 49 (2018) 5815-5822. DOI: 10.1007/s11661-018-4865-z.

[11] B. Farhoodi, R. Raiszadeh, M. H. Ghanaatian, Role of Double Oxide Film Defects in the Formation of Gas Porosity in Commercial Purity and Sr-containing Al Alloys, Journal of Materials Science and Technology 30 (2014) 154-162. DOI: 10.1016/j.jmst.2013.09.001.

[12]W. D. Griffiths, R. Raiszadeh, Hydrogen, Porosity and Oxide Film Defects in Liquid Al, Journal of Materials Science 44 (2009) 3402-3407. DOI: 10.1007/s10853-009-3450-7

[13] A.M. Samuel, F.H. Samuel, H.W. Doty, S. Valtierra, Influence of Oxides on Porosity Formation in Srtreated Alloys, International Journal of Metalcasting 11 (2017) 729-742. DOI: 10.1007/s40962016-0118-3.

[14]P. Yousefian, M. Tiryakioğlu, Pore Formation During Solidification of Aluminum: Reconciliation of Experimental Observations, Modeling Assumptions, and Classical Nucleation Theory, Metallurgical and Materials Transactions A 49 (2018) 563-575. DOI: 10.1007/s11661-017-4438-6.

[15] E. Erzi, M. Tiryakioğlu, On the Fracture Pressure of Liquid Metals, Materials Science and Technology 35/13 (2019) 1656-1659. DOI: 10.1080/02670836.2019.1646010.

[16] M. Tiryakioğlu, The Myth of Hydrogen Pores in Aluminum Castings, In: M. Tiryakioğlu, W. Griffiths, M. Jolly (Eds.), Shape Casting, The Minerals, Metals \& Materials Society, (2019) 143-150. DOI: 10.1007/978-3-030-06034-3_14.

[17] J. Campbell, "Stop Pouring, Start Casting", International Journal of Metalcasting 6 (2012) 7-18. DOI: $10.1007 /$ BF03355529

[18] J. Campbell, Entrainment Defects, Materials Science and Technology 22 (2006) 127-145. DOI: 10.1179/174328406X74248.

[19] J. Campbell, Defects in Aluminum Alloy Castings, Encyclopedia of Aluminum and Its Alloys, Taylor \& Francis, (2019) 587-592 DOI: 10.1201/9781351045636-140000253

[20] G. Gyarmati, Gy. Fegyverneki, T. Mende, M. Tokár, Characterization of the Double Oxide Film Content of Liquid Aluminum Alloys by Computed Tomography, Materials Characterization 157 (2019) 109925. DOI: 10.1016/j.matchar.2019.109925

[21] G. Gyarmati, T. Mende, Gy. Fegyverneki, M. Tokár, Liquid Metal Quality Assessment with X-ray Computed Tomography, The World Foundry Organization Technical Forum and 59th International Foundry Conference Portoroz, Slovenian Foundrymen Society, (2019)

[22] S. Fox, J. Campbell, Visualisation of Oxide Film Defects During Solidification of Aluminium Alloys, Scripta Materialia 43 (2000) 881-886. DOI: 10.1016/S1359-6462(00)00506-6 
International Journal of Engineering and Management Sciences (IJEMS) Vol. 5. (2020). No. 2 DOI: 10.21791/IJEMS.2020.2.18.

[23] M. Uludağ, R. Çetin, D. Dişpinar, M. Tiryakioğlu, On the Interpretation of Melt Quality Assessment of A356 Aluminum Alloy by the Reduced Pressure Test: The Bifilm Index and Its Physical Meaning, International Journal of Metalcasting 12 (2018) 853-860. DOI: 10.1007/s40962-018-0217-4

[24] G. K. Sigworth, The Modification of Al-Si Casting Alloys: Important Practical and Theoretical Aspects, International Journal of Metalcasting 2 (2008) 19-40. DOI: 10.1007/BF03355425

[25] S. Moniri, A. J. Shahani, Chemical Modification of Degenerate Eutectics: A Review of Recent Advances and Current Issues, Journal of Materials Research 34 (2019) 20-34. DOI: 10.1557/jmr.2018.361

[26] M. Tokár, Gy. Fegyverneki, V. Mertinger, Investigation of the Common Modification Effect of Strontium and Antimony on the Structure in Case of Al-Si Alloy. Materials Science Forum 812 (2015) 393-398. DOI: 10.4028/www.scientific.net/MSF.812.393

[27] S. D. McDonald, A. K. Dahle, J. A. Taylor, D. H. StJohn, Modification-Related Porosity Formation in Hypoeutectic Aluminum-Silicon Alloys, Metallurgical and Materials Transactions B 35 (2004) 1097-1106. DOI: 10.1007/s11663-004-0065-x

[28] R. Fuoco, E. R. Correa, H. Goldenstein, Effect of Modification Treatment on Microporosity Formation in 356 Al Alloy, Part I: Interdendritic Feeding Evaluation, AFS Transactions 104 (1996) 1151-1158.

[29] L. Lu, K. Nogita, S. D. McDonald, A. K. Dahle, Eutectic Solidification and Its Role in Casting Porosity Formation, JOM 56 (2004) 52-58. DOI: 10.1007/s11837-004-0254-8

[30] J. Campbell, Modification of Al-Si Alloys, AFS Transactions 119 (2011) 171-176.

[31] J. Campbell, M. Tiryakioğlu, Review of Effect of P and Sr on Modification and Porosity Development in Al-Si Alloys, Materials Science and Technology 26 (2010) 262-268. DOI: $10.1179 / 174328409 \times 425227$

[32] D. Emadi, J. E. Gruzleski, P. Pekguleryuz, Melt Oxidation Behavior and Inclusion Content in Unmodified and Sr-modified A356 Alloy - Their Role in Pore Nucleation, AFS Transactions, 104 (1996) 763-768.

[33] S. M. Miresmaeili, J. Campbell, S. G. Shabestari, S. M. A. Boutorabi, Precipitation of Sr-rich Intermetallic Particles and Their Influence on Pore Formation in Sr-modified A356 Alloy, Metallurgical and Materials Transactions A 36 (2005) 2341-2349. DOI: 10.1007/s11661-0050106-3

[34] Q. Wang, Q. Hao, W. Yu, Effect of Strontium Modification on Porosity Formation in A356 Alloy, International Journal of Metalcasting 13/4 (2019) 944-952. DOI: 10.1007/s40962-018-00300-1

[35] S. W. Hudson, D. Apelian, Inclusion Detection in Molten Aluminum: Current Art and New Avenues for in Situ Analysis, International Journal of Metalcasting 10/ 3 (2016) 315-321. DOI: 10.1007/s40962-016-0030-x

[36] G. Gyarmati, Gy. Fegyverneki, T. Mende, M. Tokár, The Effect of Fluxes on the Melt Quality of AlSi7MgCu Alloy, International Journal of Engineering and Management Sciences (IJEMS) 4 (2019) DOI: 10.21791/IJEMS.2019.1.46. 
International Journal of Engineering and Management Sciences (IJEMS) Vol. 5. (2020). No. 2

DOI: 10.21791/IJEMS.2020.2.18.

[37] M. Djurdjevic, H. Jiang, J. Sokolowski, On-Line Prediction of Aluminum-Silicon Eutectic Modification Level Using Thermal Analysis, Materials Characterization 46/1 (2001) 31-38. DOI: 10.1016/S1044-5803(00)00090-5

[38] M. Malekan, S. G. Shabestari, Computer-Aided Cooling Curve Thermal Analysis Used to Predict the Quality of Aluminum Alloys, Journal of Thermal Analysis and Calorimetry 103/2 (2011) 453-458. DOI: $10.1007 / \mathrm{s} 10973-010-1023-2$

[39] S. Eguskiza, A. Niklas, A. I. Fernández-Calvo, F. Santos, M. Djurdjevic, Study of Strontium Fading in Al-Si-Mg and Al-Si-Mg-Cu Alloy by Thermal Analysis, International Journal of Metalcasting 9/3 (2015) 43-50. DOI: 10.1007/BF03355622

[40] G. Gyarmati, Gy. Fegyverneki, D. Molnár, M. Tokár, The Melt Cleaning Efficiency of Different Fluxes and Their Effect on the Eutectic Modification Level of AlSi7MgCu Alloy, Livarski Vestnik 66 (2019) 70-87.

[41] F. C. Robles-Hernandez, J. M. H. Ramírez, R. Mackay, Al-Si Alloys - Automotive, Aeronautical, and Aerospace Applications, Springer International Publishing AG, (2017)

[42] M. Tokár, Gy. Fegyverneki, V. Mertinger, Analysis of the Antimony and Strontium Cross-Effects in AlSi Foundry Alloys, Materials Science Forum 790-791 (2014) 464-469. DOI: 10.4028/www.scientific.net/MSF.790-791.464

[43] M. De Giovanni, J. M. Warnett, M. A. Williams, P. Srirangam, 3D Imaging and Quantification of Porosity and Intermetallic Particles in Strontium Modified Al-Si Alloys, Journal of Alloys and Compounds 727 (2017) 353-361. DOI: 10.1016/j.jallcom.2017.08.146

[44] X. Cao, J. Campbell, Oxide Inclusion Defects in Al-Si-Mg Cast Alloys, Canadian Metallurgical Quarterly 44 (2005) 435-448. DOI: 10.1179/cmq.2005.44.4.435

[45] R. Gallo, "I Have Inclusions! Get Me the Cheapest and Best Flux for Cleaning My Melt" - Is This the Best Driven, Cost Saving Approach by a Foundry?, AFS Transactions 125 (2017) 97-110.

[46] NIST Standard Reference Database Number 69, DOI: 10.18434/T4D303

[47] H. B. Esfahani, H. Doostmohammadi, R. Raiszadeh, Decrease in the Rate of Diffusion of Hydrogen through Layers of Bifilm Defects in Al Melt in the Presence of Sr, International Journal of Cast Metals Research 29 (2016) 179-185. DOI: 10.1080/13640461.2015.1125645

[48] X. Bian, Z. Zhang, X. Liu, Effect of Strontium Modification on Hydrogen Content and Porosity Shape of Al-Si Alloys. Materials Science Forum 331 (2000) 361-366. DOI: 10.4028/www.scientific.net/MSF.331-337.361 